\title{
ANGIOSTRONGILOSE ABDOMINAL: PROFILAXIA PELA DESTRUIÇÃO DAS LARVAS INFECTANTES EM ALIMENTOS TRATADOS COM SAL, VINAGRE OU HIPOCLORITO DE SÓDIO
}

\author{
Graziela Maria Zanini e Carlos Graeff-Teixeira
}

\begin{abstract}
A infecção acidental bumana pelo Angiostrongylus costaricensis ocorre com elevada prevalência em certas áreas do Brasil meridional, eventualmente se manifestando como doença abdominal severa. Profilaxia é importante, pois não bá tratamento medicamentoso. Um dos modos de transmissão é a ingestão de frutas e vegetais contaminados com a mucosidade de moluscos infectados, os bospedeiros intermediários deste parasita. Larvas de terceiro estágio obtidas do ciclo mantido em laboratório foram incubadas a $5^{\circ} \mathrm{C}$ por 12 boras, em vinagre, soluçâo saturada de cloreto de sódio e bipoclorito de sódio a 1,5\%. A viabilidade das lavvas tratadas foi testada através da inoculação em camundongos albinos. Os percentuais de larvas que estabeleceram infecção foram: $0 \%$ com bipoclorito de sódio, 1,8\% com salmora e 2,4\% com vinagre. Em conclusāo, todas as substâncias - de baixo custo e disponiveis nas äreas endêmicas - reduziram à população de larvas viâveis e podem ser úteis na descontaminaçâo de alimentos para profilaxia da angiostrongilose abdominal.
\end{abstract}

Palavras-chaves: Angiostrongilose abdominal. Contaminação alimentar. Zoonoses por helmintos.

A angiostrongilose abdominal é uma infecção causada pelo Angiostrongylus costaricensis, parasita habitual de roedores silvestres, tais como o Sigmodon bispidus na América Central e Oryzomys nigripes no sul do Brasil ${ }^{4}$. O homem pode ser hospedeiro acidental ao ingerir alimentos contaminados com larvas de terceiro estágio (L3), eliminadas com a mucosidade de moluscos terrestres, hospedeiros intermediários deste parasita ${ }^{i}$.

No Brasil, a maioria dos diagnósticos vem de estados sulinos, especialmente, do Rio Grande do Sul² e resultados de dois inquéritos soroepidemiológicos indicam que a infecção pelo $A$. costaricensis é muito comum. (C. Graeff-Teixeira: dados não publicados). Nas áreas endêmicas do Rio Grande do Sul há informações sugerindo a existência de grande número de casos que evoluem espontanemente para cura e que ficam sem

\footnotetext{
Laboratório de Parasitologia, Departamento de Ciências Microbiológicas e Curso de Pós-Graduação em Biociências. Instituto de Biociências/Pontificia Universidade Católica do Rio Grande do Sul, Porto Alegre, RS Apoio financeiro: bolsas CNPq 500893-92-6 e CAPES.

Endereço para correspondência: Dr. Carlos Graeff-Teixeira. Av. Ipiranga 6681, 90619-900 Porto Alegre, RS.

Recebido para publicação em 10/02/95
}

diagnóstico. Isto porque os casos complicados por obstrução e/ou perfuração intestinal são relativamente raros e os únicos em que se faz diagnóstico parasitológico, através do exame anátomo-patológico ${ }^{3}$.

O tratamento anti-helmintico é contraindicado, pois o parasita localiza-se no interior de ramos da artéria mesentérica e a sua morte agrava as lesões, podendo levar a quadros de trombose arterial aguda ${ }^{6}$. Nesta situação, 0 estabelecimento de medidas profiláticas da angiostrongilose abdominal é de grande importância. Morera, em 1980, apresentou dados indicando a possível eficácia do resfriamento de verduras como profilaxias.

O objetivo deste trabalho é avaliar substâncias de uso comum pela população, como inibidoras da viabilidade de larvas $\mathrm{L} 3 \mathrm{de}$ A. costaricensis.

\section{MATERIAL E MÉTODOS}

A cepa Santa Rosa do $A$. costaricensis vem sendo mantida em laboratório, através de passagens por camundongos albinos e lesmas coletadas na natureza: Pbyllocaulis soleiformis. As larvas foram obtidas pela digestão artificial dos molus $\cos ^{7}$ e um lote foi imediatamente inoculado, 16 larvas por animal, em 
Zanini GM, Graeff-Teixeira C. Angiostrongilose abdominal: profilaxia pela destruição das larvas infectantes em alimentos tratados com sal, vinagre ou hipoclorito de sódio. Revista da Sociedade Brasileira de Medicina Tropical 28:389-392, out-dez, 1995.

camundongos para teste de viabilidade (Grupo $1=$ controle 1 ). As demais larvas foram incubadas a $5^{\circ} \mathrm{C}$ por um periodo de 12 horas, em água destilada (controle 2), vinagre de vinho tinto (Vega, Pelotas, RS), solução saturada de sal de cozinha iodado (Cisne, Cabo Frio, RJ) e solução de hipoclorito de sódio a $1,5 \%(\mathrm{v} / \mathrm{v} ; 15 \mathrm{ml}$ em $1000 \mathrm{ml}$ de água destilada) (água sanitária Clorissol lote E 3/4, Clorosul S/A, Porto Alegre, RS).

Após a incubação, 16 larvas por animal foram inoculadas via oral em 4 grupos de 12 camundongos: Grupo 2: controle 2; Grupo 3: $\mathrm{NaCl}$; Grupo 4: vinagre; Grupo 5: hipoclorito de sódio. Entre o $30^{\circ}$ e $35^{\circ}$ dias de infecção, os camundongos foram sacrificados para exame dos ramos arteriais mesentéricos com contagem das formas adultas ao microscópio estereoscópico e observação macroscópica das lesões existentes.

O teste de cada substância foi repetido três vezes. O número total de animais em cada Grupo (Tabela 1) variou devido: 1) a limitação do número de camundongos disponíveis para os experimentos, o que levou à redução do número de animais no Grupo 1, de 12 para 6; 2) na segunda repetição, não havia número suficiente de larvas para construir todos os grupos, tendo sido feito um experimento isolado testando vinagre, com os controles 1 e 2.

\section{RESULTADOS}

A média dos resultados de três repetições, para cada substância testada, está expressa nas Tabelas 1 e 2 . A mortalidade variou de 16 a $50 \%$ nos grupos controles e esteve sempre abaixo de $16 \%$ nos grupos tratados (Tabela 1).

Para expressar a eficácia larvicida, em cada Grupo, considerou-se o número de vermes adultos em relação ao número de larvas inoculadas, como "percentagem de larvas que produziu infecção". Também, foi analisada ocorrência de animais livres de infecção (Tabela 2).

À necrópsia dos animais infectados (Tabela 3) foram observados espessamento e dilatação dos ramos arteriais mesentéricos; no mesentério: opacidades e aderências; na parede intestinal: lesões hemorrágicas, áreas de congestão e necrose, espessamento e micronodulações de cor branca além de aumento de tamanho dos linfonodos na raiz do mesentério. Muitos animais apresentaram severas lesões hepáticas e, eventualmente, também no baço. O número e intensidade das lesôes foram maiores nos grupos controles. Em um dos animais inoculados com larvas, tratadas com hipoclorito de sódio, foi observado apenas discreto espessamento do tronco principal da artéria, sem ter sido encontrado verme.

Tabela 1. Mortalidade de camundongos inoculados com lavas $L 3$ de A. costaricensis, incubadas por 12 boras com: água destilada (controle2), soluçâo saturada de cloreto de sódio (NaCl). vinagre e soluçăo $1,5 \%$ de bipoclorito de sódio (NaHClo 3 ). Larvas recém isoladas, iấo-incubadas. constituem o Controle 1 .

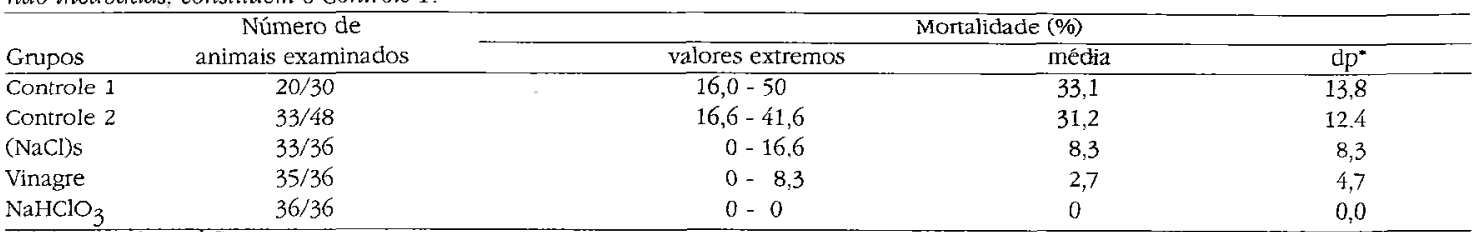

${ }^{*}(\mathrm{dp})=$ desvio padrăo

Tabela 2 - Resultados do teste de viabilidade das larvas $L 3$ de A. costaricensis inoculadas em camundongos. previamente tratadas com ägua destilada (Controle 2), cloreto de sódio (NaCD), vinagre e bipoclorito de sódio (NaHClO, a $1.5 \%$. Sāo apresentados os percentuais de animais livres de infecção e de larvas que evoluiram a vermes adultos. Lavvas recém-isoladas e nào tratadas constituem o Controle 1.

\begin{tabular}{|c|c|c|c|c|c|c|}
\hline \multirow[t]{2}{*}{ Grupos } & \multicolumn{3}{|c|}{$\begin{array}{c}\text { latvas recuperadas como } \\
\text { vermes adultos (\%) }\end{array}$} & \multicolumn{3}{|c|}{ Animais nāo-infectados (\%) } \\
\hline & valores extremos & média & $\mathrm{dp}$ & valores extremos & média & $\mathrm{dp}$ \\
\hline Controle 1 & $22,9-98,4$ & 51,9 & $32, \overline{4}$ & $0-0$ & 0 & 0 \\
\hline Controle 2 & $22,1-34,8$ & 26.2 & 5,8 & $0-3$ & 2 & 4,1 \\
\hline$(\mathrm{NaCl}) \mathrm{s}$ & $0-5,6$ & 1,8 & 3,2 & $60-100$ & 86,6 & 23 \\
\hline Vinagre & $0-5,2$ & 2,4 & 2,6 & $50-100$ & 74.2 & 25 \\
\hline $\mathrm{NaHClO}_{3}$ & $0-0$ & 0 & 0 & $100-100$ & 100 & 0 \\
\hline
\end{tabular}


Zanini GM, Graeff-Teixeira C. Angiostrongilose abdominal: profilaxia pela destruição das larvas infectantes em alimentos tratados com sal, vinagre ou hipoclorito de sódio. Revista da Sociedade Brasileira de Medicina Tropical 28:389-392, out-dez, 1995.

Tabela 3 - Lesões macroscópicas do intestino observadas nos animais infectados com as larvas tratadas com água destilada (Controle 2) cloreto de sódio (NaCl), vinagre e solução de bipoclorito de sódio ( $\mathrm{NaHClO}_{3}$ ). Lañas recém-isoladas e näo-trataaas constituem o Controle 1 .

\begin{tabular}{|c|c|c|c|c|c|}
\hline Local & Controle 1 & Controle 2 & $(\mathrm{NaCl}) \mathrm{S}$ & Vinagre & $\mathrm{NaHClO}_{3}$ \\
\hline Pontilhado branco & $17 / 2 \overline{0}$ & $29 / 33$ & $3 / 33$ & $6 / 35$ & $0 / 36$ \\
\hline Pontilhado hemorrágico & $12 / 20$ & $27 / 33$ & $3 / 33$ & $5 / 35$ & $0 / 36$ \\
\hline Área congesta ou com necrose & $1 / 20$ & $0 / 33$ & $0 / 33$ & $0 / 35$ & $0 / 36$ \\
\hline Espessamento arterial & $19 / 20$ & $28 / 33$ & $3 / 33$ & $8 / 35$ & $1 / 36$ \\
\hline Aumento dos linfonodos & $10 / 20$ & $14 / 33$ & $3 / 33$ & $7 / 35$ & $0 / 36$ \\
\hline Espessamento da parede & $13 / 20$ & $26 / 33$ & $2 / 33$ & $5 / 35$ & $1 / 36$ \\
\hline Opacidades do mesentério & $9 / 20$ & $10 / 33$ & $4 / 33$ & $5 / 35$ & $0 / 36$ \\
\hline Aderências & $6 / 20$ & $3 / 33$ & $1 / 33$ & $0 / 35$ & $0 / 36$ \\
\hline
\end{tabular}

\section{DISCUSSÃO}

Supôe-se que a angiostrongilose abdominal possa ser transmitida ao homem de quatro maneiras: 1) pela ingestão de alimentos contaminados com muco contendo a larva de terceiro estágio; 2) por contágio direto, quando da manipulação de moluscos infectados; 3) pela ingestão do próprio molusco; 4) pela água. Não há estudos detalhados investigando a ocorrência e importância destes supostos modos de infeç̧ão. A água pode conter as larvas L3 e se isto ocorrer na natureza, os estudos epidemiológicos teriam que dirigir atenção a moluscos aquáticos como vetores e a filtragem ou fervura da água seria recomendável. A ingestão do molusco pode dar-se de modo acidental, como em crianças pequenas ou diminutos moluscos em meio a verdura, ou proposital, como parte da culinária. A manipulação de moluscos ocorre tipicamente entre pescadores amadores, na região norte do Rio Grande do Sul, que os utilizam como iscas. Muitas crianças na área rural brincam com moluscos vivos, como o Megalobulimus sp. Seria importante dispor de reagentes larvicidas no preparo das verduras e frutas que são consumidas cruas, pois o muco, translúcido e aderido firmemente, pode passar desapercebido e não ser removido por lavagem.

Morera, em 1980, propôs o resfriamento em geladeira das verduras, por cerca de 12 horas, como medida preventivas. Richinitti e GraeffTeixeira (dados não publicados) demonstraram que a ação do frio $\left(5^{\circ} \mathrm{C}\right)$ pode reduzir de 98 a $100 \%$ da viabilidade das larvas, somente após três dias, o que torna o procedimento pouco prático.
A ação larvicida da solução de hipoclorito de sódio a 1,5\% ficou evidente: as larvas incubadas com este reagente não estabeleceram infecção em camundongos. Tal concentração é recomendada na profilaxia do cólera ${ }^{8}$. Com eficácia menor, vinagre e salmora não apresentaram diferenças significativas entre si, embora a redução de larvas viáveis tenha sido grande (91 e 97\%). Nâo se conhece a correlação entre o número de larvas e a probabilidade de estabelecer-se a infecção no homem. Entretanto, é possível que a carga parasitária seja importante fator na patogenia, tornando útil um procedimento que reduza significativamente o número de larvas viáveis. Há que se levar em conta que a utilização destes reagentes não deverá ser recomendada de forma isolada e que a inspeção e lavagem dos alimentos serão sempre o primeiro passo para a profilaxia desta e outras parasitoses.

O resultado obtido com o vinagre foi inesperado, já que no ciclo natural as larvas L3 estabelecem infecção no vertebrado após ingestão, passando pelo ambiente ácido do estômago, onde o $\mathrm{pH}$ baixo poderia inclusive funcionar como sinal para ativação $0^{5}$. Morera, em 1980, testou ácido acético e não obteve ação larvicida". É difícil propor alguma explicação, enquanto não for dissecado o processo de inativação das larvas, especialmente, em relação ao vinagre, que é uma mistura não padronizada de vârias substâncias, além do ácido acético.

O tempo de incubação de 12 horas é inviável do ponto de vista prático, na recomendação para a população tratar as verduras. Estão em andamento experimentos visando estabelecer o tempo e concentraçôes 
Zanini GM, Graeff-Teixeira C. Angiostrongilose abdominal: profilaxia pela destruição das larvas infectantes em alimentos tratados com sal, vinagre ou bipoclorito de sódio. Revista da Sociedade Brasileira de Medicina Tropical 28:389-392, out-dez, 1995.

minimas eficazes, inclusive variando a temperatura. Este trabalho constituiu num estudo piloto, destinado a estabelecer a eficácia larvicida em condições extremas de tempo (12 horas), temperatura $\left(5^{\circ} \mathrm{C}\right)$ e concentração dos reagentes testados.

Tanto o vinagre puro, como a salmora apresentaram ação deletéria sobre as larvas e seu uso deve ser recomendado nas áreas endêmicas, mesmo sem garantia de segurança total na eliminação das formas infectantes, pela razão de que o tratamento das verduras com estes reagentes deve ser parte de um conjunto de medidas profiláticas. O hipoclorito de sódio usado na concentração de 1,5\% (v/v), é o mais eficaz e foi empregada a mesma concentração recomendada para lavar hortaliças e verduras, dentre os cuidados com o cólera ${ }^{8}$. Com qualquer dos reagentes, os alimentos teriam de ficar em imersão e, obviamente, seriam enxaguados em água fervida antes do consumo.

Numa parasitose de provável alta prevalência, nos focos de transmissão, com inúmeros casos de regressão espontânea, sem tratamento anti-helmíntico adequado, resta a intervenção primária na história natural, com a prevenção da infecção. Esta é a importância da identificação de atividade inibitória da viabilidade das formas infectantes (L3) em substâncias de baixo custo e disponiveis à população vivendo nas áreas de transmissão da angiostrongilose abdominal.

\section{SUMMARY}

There is a bigh prevalence of accidental buman infection with Angiostrongylus costaricensis in some areas in southern Brazil and sometimes it presents as severe intestinal disease. Propbylaxis is important since there is no medical treatment for the disease. The ingestion of fruits and vegetables contaminated with the mucous secretion of infected molluscs (the intermediate bosts) is one of the proposed modes of transmission. Third stage larvae were incubated at $5^{\circ} \mathrm{C}$ for 12 bours, in solutions of saturated sodium chloride, vinegar and sodium bypochlorite $1.5 \%$. The larvae bad their viability tested through inoculation into albino mice. The percentage of larvae that established infection were $0 \%$ in the group treated with sodium bypochloride, $1.8 \%$ with $\mathrm{NaCl}$ and $2.4 \%$ with vinegar. In conclusion, all substances tested reduced the population of viable larvae and may be useful in food decontamination, as a prophylactic measure for abdominal angiostrongylosis.

Key-words: Abdominal angiostrongylosis. Foodborne diseases. Helminthic zoonosis.

\section{AGRADECIMENTOS}

À Eva Medeiros pelo a poio técnico.

\section{REFERÊNCIAS BIBLIOGRÁFICAS}

1. Graeff-Teixeira C, Avila-Pires FD, Machado RCC, Camillo-Coura L, Lenzi HL. Identificação de roedores silvestres como hospedeiros do Angiostrongylus costaricensis. Revista do Instituto de Medicina Tropical de São Paulo 32:147-150, 1990

2. Graeff-Teixeira C, Camilo-Coura L, Lenzi HL. Angiostrongilíase abdominal - uma nova parasitose no sul do Brasil. Revista da AMRIGS, Porto Alegre 35:91-98, 1991.

3. Graeff-Teixeira C, Camilo-Coura L, Lenzi HL. Histopathological criteria for the diagnosis of abdominal angiostrongyliasis. Parasitology Research 77:606-611, 1991.

4. Morera P. Life history and redescription of Angiostrongylus costaricensis (Morera \& Céspedes, 1971). The American Journal of Tropical Medicine and Hygiene 22:613-621, 1973.

5. Morera P. Angiostrongiliasis abdominal: Transmision y observaciones sobre su posible control. Control y erradicacion de enfermedades infecciosas. In: Resúmenes del Simposio Internacional OMS/OPS, Série de copublicaciones de la OPS, n 1, 1986.

6. Morera P, Bontempo I. Accion de algunos anthihelminticos sobre Angiostrongylus costaricensis. Revista Medica Hospital Nacional de Niños de Costa Rica 20: 165-174, 1986.

7. Wallace GD, Rosen $L$. Techniques for recovering and identifying larvae of Angiostrongylus cantonensis from molluscs. Malacologia 7:427$438,1969$.

8. Zenebon O, Duarte de Maio F, Sakuma AM, Rosa E. Determinação de mercúrio em águas sanitárias comercializadas em região do sudeste do Brasil. Revista de Saúde Pública 28:127-130, 1994. 